\title{
Research on Targeted Acidizing Technology in Long Horizontal Section of Carbonate Reservoir
}

\author{
Chao Wang ${ }^{1}$, Changjun Long ${ }^{2 *}$, Jianli Zhang ${ }^{1}$, Jie Xiao ${ }^{3}$, Zhengdong Xu ${ }^{2}$, Feng Yan ${ }^{4}$ \\ ${ }^{1}$ Institute of Engineering and Technology Petrochina Research Institute of Exploration and Development, Beijing, 100089, China; \\ ${ }^{2}$ Engineering Technology Research Institute of Huabei Oilfield Company, Hebei Renqiu, 062552, China; \\ ${ }^{3}$ Exploration and Development Research institute of HuaBei Oilfield Company, Hebei Renqiu, 062550, China; \\ ${ }^{4}$ The Geology Institute of Second Exploitation Factory of Huabei Oulfield Company, Hebei Bazhou, 065700, China;
}

\begin{abstract}
The upper layer of Oil field A is developed by horizontal linear well pattern with long well segment. After completion, there is relatively serious formation damage, and the tested epidermal factor is up to 6.21 on average. Due to the length of horizontal well section and the serious vertical heterogeneity of formation, some strata were over-acidized in the early stage, so it was very difficult to distribute acid evenly. For this reason, the low contribution layer of horizontal section was determined by using amino carboxylic acid system and coiled tubing hydrojet acidification process, combined with reservoir characteristics, and the spindle-type acid distribution method was adopted to optimize nozzle combination parameters to predict construction displacement and ground construction pressure. The laboratory experiment was carried out to compare with the conventional acid system for core displacement experiment. The acid could form acid-etch wormhole, effectively extend the acid-action distance, and achieve the purpose of slow and deep penetration.
\end{abstract}

\section{Introduction}

As the first foreign oil cooperation project after the war in Iraq, this oil field was jointly developed by China Oasis Oil Company and Iraq Northern Oil Company [1-2]. The field is located in Wasit province in south-central Iraq, about $180 \mathrm{~km}$ northwest of Baghdad. The reservoir of this oil field belongs to the carbonate reservoir of multi-layer series with middle-high porosity and low permeability. It is developed with linear pattern of horizontal well in long well section, and the horizontal well section is $800-1000 \mathrm{~m}$ long. The reservoir is buried at a depth of $2,600-3,200 \mathrm{~m}$ and the temperature is between $80-90^{\circ} \mathrm{C}$. The formation water salinity is $120300-209,000 \mathrm{mg} / \mathrm{L}$. Bioclastic limestone is mainly developed in the reservoir, with strong reservoir heterogeneity. The average porosity is $16.2 \%$, and the average permeability is $5.5 \mathrm{md}$, which belongs to the mesoporous and low-permeability reservoir and is a typical pore carbonate reservoir [3-5].

\section{Study on acid system}

Conventional hydrochloric acid will react quickly with rocks in the open hole section after being injected into the horizontal well section and become a residual acid with no corrosion ability. If the concentration of hydrochloric acid is increased, excessive corrosion and pipeline corrosion will easily occur. Aiming at the problems existing in conventional acidizing of carbonate reservoir, the optimal formulation system of acid solution was carried out in the laboratory.

\subsection{Optimization of acid formula}

By a large number of experimental studies and screening, select a main agent for the amino acid type of chelating acid system, the chelating agent to have strong ability of chelating metal ions, friendly to environment, easy biodegradation, chelation and acidification work together in the reservoir, at the same time optimizing various additive components, finally realizes the lower acid salt reaction rate, the purpose of effective deep reservoir etching loop hole. Therefore, the optimal formula of acid solution is as follows: $8 \%-10 \%$ amino carboxylic acid $+1 \%$ drainage aid $+1 \%$ iron ion stabilizer.

\subsection{Chelation performance test}

Compared with other common chelating agents. The comparison results are shown in Table 1, such chelating agents have a high chelating ability for $\mathrm{Ca}^{2+}, \mathrm{Fe}^{3+}$ and $\mathrm{Mg}^{2+}$, and can effectively reduce the generation of metal fluoride, fluorosilicate, fluoroaluminate and hydroxide precipitation in the reservoir, which is beneficial to reduce the corrosion effect on the pipe string and other equipment. 
Table 1. Chelating conditions of $\mathrm{Ca}^{2+}, \mathrm{Fe}^{3+}$ and $\mathrm{Mg}^{2+}$ by various chelating agents

\begin{tabular}{crcc}
\hline Chelating agent type & $\mathrm{Ca}^{2+}$ tolerance $(\mathrm{mg} / \mathrm{g})$ & $\mathrm{Mg}^{2+}$ tolerance $(\mathrm{mg} / \mathrm{g})$ & $\mathrm{Fe}^{3+}$ tolerance $(\mathrm{mg} / \mathrm{g})$ \\
EDTA & 140 & 65 & 145 \\
HEDTA & 116 & 70 & 165 \\
NTA & 146 & 55 & 215 \\
DTPA & 104 & 104 & 115 \\
Amino carboxylic acid & 253 & 158 & 442.5 \\
\hline
\end{tabular}

\subsection{Corrosion inhibition ability test}

In carbonate reservoirs, acidizing and stimulation with conventional hydrochloric acid system can cause many problems. In order to reduce the corrosion of the equipment and construction pipe string caused by long time acid injection, the corrosion ability of 4-hour amino-carboxylic acid system under the condition of

Table 2. Acid corrosion test results

\begin{tabular}{cccccc}
\hline Test number & $\begin{array}{c}\text { Corrosion } \\
\text { weight before } \\
(\mathrm{g})\end{array}$ & $\begin{array}{c}\text { Corrosion } \\
\text { weight after }(\mathrm{g})\end{array}$ & $\begin{array}{c}\text { Surface area } \\
(\mathrm{mm} 2)\end{array}$ & $\begin{array}{c}\text { Corrosion rate } \\
\mathrm{g} /(\mathrm{m} 2 \cdot \mathrm{h})\end{array}$ & Remark \\
1 & 11.1832 & 11.1812 & 1326.4826 & 0.37694 & $\mathrm{BG13Cr}$ \\
2 & 11.4448 & 11.4408 & 1332.4274 & 0.75051 & $\mathrm{BG13Cr}$ \\
3 & 11.1659 & 11.1512 & 1328.8648 & 2.76552 & $\mathrm{SB} 13 \mathrm{Cr}$ \\
4 & 10.9726 & 10.9614 & 1325.2232 & 2.11285 & $\mathrm{SB} 13 \mathrm{Cr}$ \\
\hline
\end{tabular}

\subsection{Vermicular hole etching performance experiment}

The core flow experiment was used to study and analyze the vermicular etching performance of the amino-carboxylic acid system and compare it with that of the hydrochloric acid system. The selected core is relatively dense, with no pores or fractures observed on the surface and a permeability of about $1 \mathrm{mD}$. Firstly, hydrochloric acid system with $10 \%$ concentration was selected for displacement, as shown in Figure 1. Within a short period of time, the pressure was close to the maximum acquisition pressure of the experimental equipment, and the pressure remained unchanged all the time, with only a small amount of liquid flowing out. After the acid injection was stopped, the core was taken out for observation, and it was found that the rock surface was slightly corroded after the hydrochloric acid

displacement, which was only limited to the surface and did not carry out deep propulsion. See Table 3 for examples. The results showed that the vermiporeum was not etched in the hydrochloric acid system.

The amino carboxylic acid system was changed for displacement. Similar to hydrochloric acid in the early stage, the pressure rose rapidly, but dropped sharply when the pressure rose to $15 \mathrm{MPa}$, and then the pressure continued to decline. See Figure 2. A large number of bubbles and acid flowed out of the outlet end, reflecting the formation and extension process of lumbrical pores. After the core is taken out, it is found that tiny pore structures appear at the core injection end, and large pores are formed along the axial direction on the side of the core, which greatly improves the core seepage capacity, and typical acid erosion pores appear, as shown in Table 3 . $120^{\circ} \mathrm{C}$ was studied. The corrosion rate test results are shown in Table 2. The results show that the acid system has efficient corrosion inhibition performance, and the corrosion rate is lower than $3 \mathrm{~g} /(\mathrm{m} 2 . \mathrm{h})$ under high temperature conditions, which conforms to industry standard and can effectively protect equipment and string.

Table3.Amino carboxylic acid and hydrochloric acid system react with core

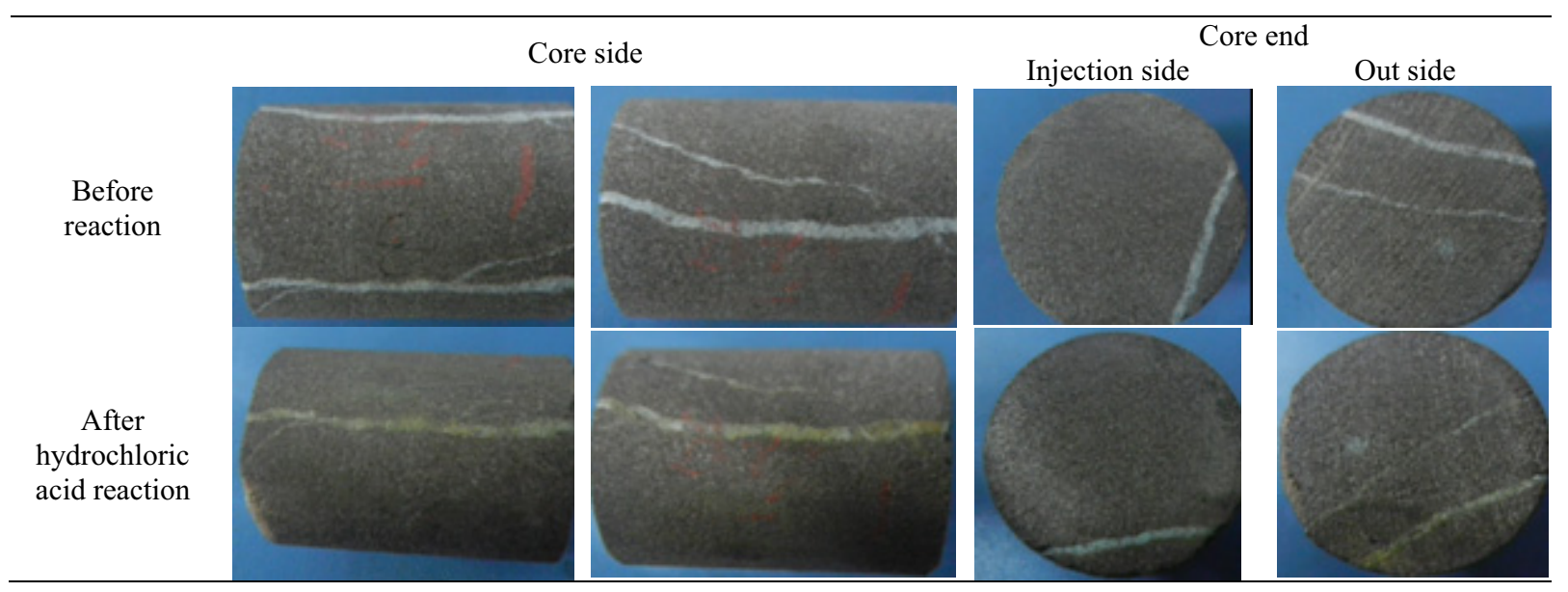




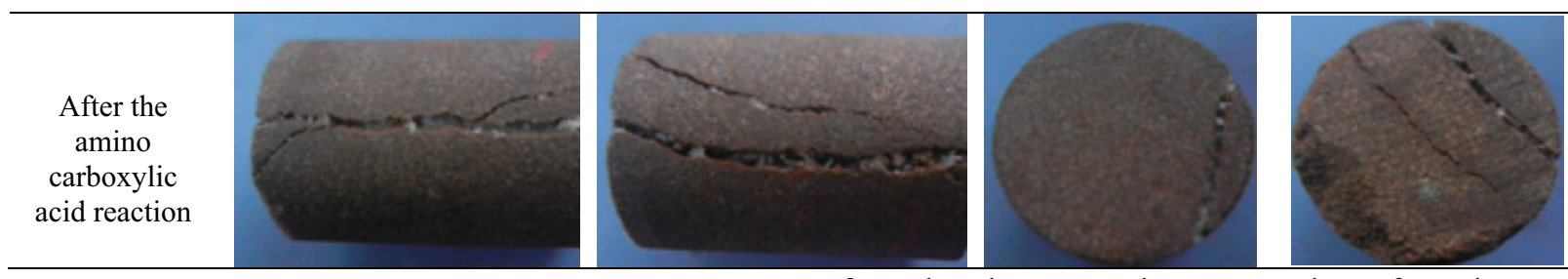

of nozzles, the greater the pressure drop of nozzles.

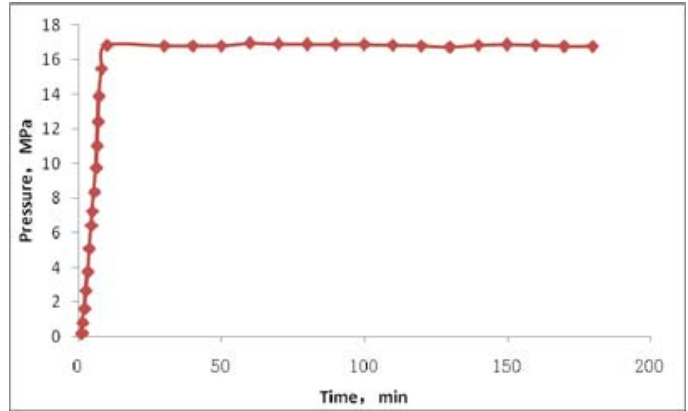

Figure1.Hydrochloric acid system pressure curve

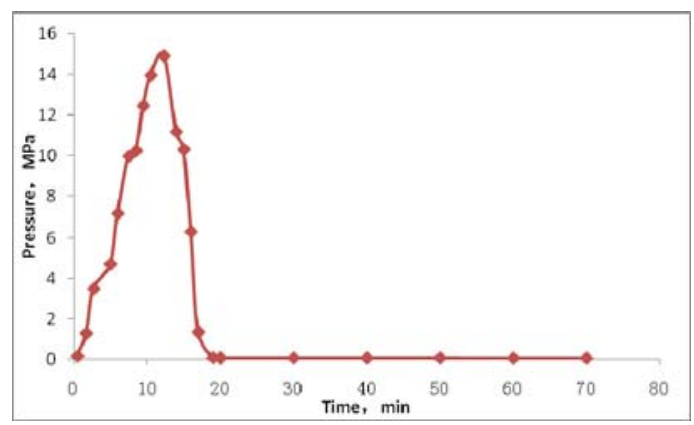

Figure2.Aminocarboxylicacid system pressure cure

\section{Study on acidizing process}

Dynamic fluid energy is used to transfer the fluid to the selected fracture-making point to open the fracture. The acid strength of each section is flexibly controlled to form (spindle type) acid distribution form (usually to imitate horizontal well damage form), so as to achieve good acidification effect with less acid.

Therefore, in the process of coiled tubing back pumping acidification, the author considers adding hydraulic jet device to the coiled tubing to create joints, so as to create acid-etched points or cracks for the working fluid.

\subsection{Design of injection parameters}

The annular pressure is $5 \mathrm{MPa}$, and the influence of the pressure inside the coiled tubing on the pressure inside the hole is $20-35 \mathrm{MPa}$. According to the experimental results (Figure. 3), as the pressure drop of the nozzle increases, the pressure difference inside the nozzle also increases, and the pressure drop on the water jet line also increases. If the diameter of the nozzle remains unchanged, the pressure drop of the nozzle is in direct proportion to the displacement. If the pressure drop of the nozzle is to be increased, the construction displacement needs to be increased. The less the number

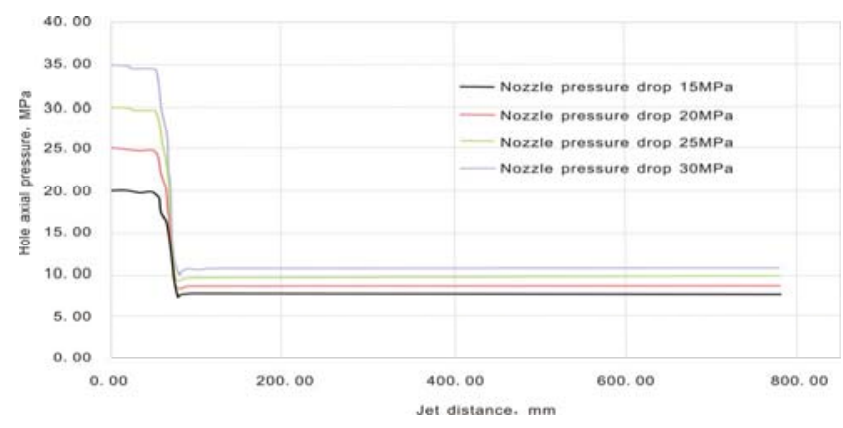

Figure 3. Different nozzle pressure drops correspond to the nozzle pressure distribution curve

\subsection{Calculation of flow friction}

Take 2 in coiled tubing as an example, the outer diameter is $50.8 \mathrm{~mm}$, the wall thickness is $3.96 \mathrm{~mm}$, the inner diameter is $42.88 \mathrm{~mm}$, the total length of coiled tubing is $2000 \mathrm{~m}$, the formation is $1000 \mathrm{~m}$, the drum diameter is $1.93 \mathrm{~m}$, the working fluid is amino carboxylic acid system, the displacement is $1.2 \mathrm{~m} 3 / \mathrm{min}$, the viscosity of clear water is $1.003 \mathrm{Mpa} . \mathrm{s}$, the density is $1.0 \mathrm{~g} / \mathrm{cm} 3$. The acid concentration was $5.0 \mathrm{~kg} / \mathrm{m} 3$ and the drag reduction ratio was 0.3856 .

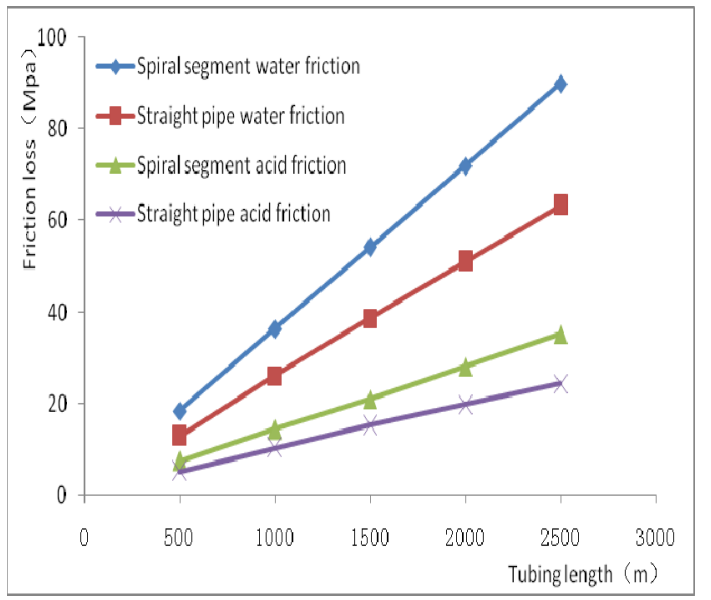

Figure4.Diagram of frictional resistance and tubing length for different fluids 


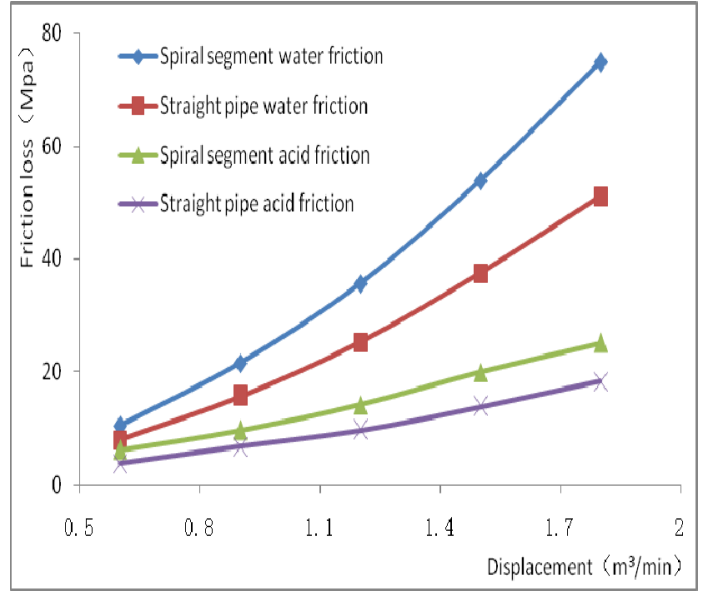

Figure5.Diagram of frictional resistance and flow rate of different fluids

Contrast acid and water in a straight pipe and spiral section of the friction loss (figure 4) can be found that emissions of certain cases, the straight pipe and spiral section of friction increases with the increase of tubing length and friction losses than the acid water along the big, straight pipe and spiral section than the friction loss along the big, analysis the fluid in the helical tube secondary flow along the pipe cross section, part of the friction loss.

As can be seen from figure 5, the larger the displacement is, the greater the friction loss along the process is, and the pressure loss of clean water in the spiral section is the largest, while the friction loss of acid liquid in the straight section is the smallest. Therefore, in the use of coiled tubing acidification construction, it is necessary to select an appropriate coiled tubing length in combination with the depth of the well section, so as to effectively reduce the friction loss of the spiral section.

\subsection{Construction displacement and ground pressure prediction}

For coiled tubing of the same size (take 2 in as the following experimental results), the larger the displacement, the greater the friction of liquid along the process, and the higher the construction pressure on the ground. Therefore, the prediction of construction displacement and ground pressure is of great significance to the selection of surface wellhead and the control of construction pressure. Therefore, the ground pressure under different nozzle combinations and different construction displacement is simulated.

Table4. Different nozzle combinations of the construction displacement and ground pressure

\begin{tabular}{cccccc}
\hline $\begin{array}{c}\text { Nozzle } \\
\text { combination }\end{array}$ & $\begin{array}{c}\text { Flow rate } \\
(\mathrm{m} 3 / \mathrm{min})\end{array}$ & $\begin{array}{c}\text { Ground pressure } \\
(\mathrm{MPa})\end{array}$ & $\begin{array}{c}\text { Nozzle } \\
\text { pressuredrop } \\
(\mathrm{Mpa})\end{array}$ & $\begin{array}{c}\text { Friction } \\
(\mathrm{Mpa})\end{array}$ & $\begin{array}{c}\text { Annulus } \\
\text { pressure } \\
(\mathrm{Mpa})\end{array}$ \\
$\begin{array}{c}3 \times 4.5 \mathrm{~mm} \\
3 \times 5 \mathrm{~mm}\end{array}$ & 0.7 & 65.18 & 37.91 & 16.68 & 11.24 \\
$3 \times 5.5 \mathrm{~mm}$ & 0.8 & 62.35 & 32.48 & 19.37 & 11.26 \\
$3 \times 6 \mathrm{~mm}$ & 0.9 & 60.77 & 28.08 & 22.29 & 11.26 \\
$4 \times 4.5 \mathrm{~mm}$ & 1.1 & 68.58 & 29.62 & 28.79 & 11.25 \\
$4 \times 5 \mathrm{~mm}$ & 0.9 & 67.9 & 35.25 & 22.29 & 11.25 \\
\hline
\end{tabular}

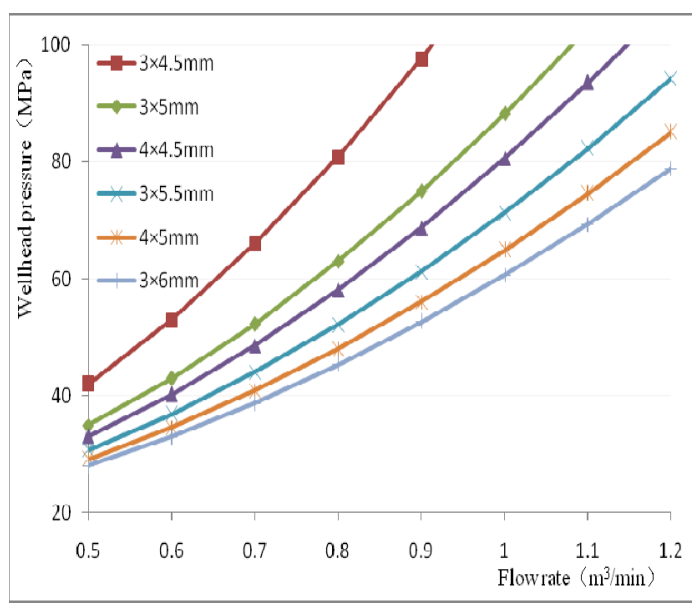

Figure6.Diagramof relationship between lower ground pressure and flowrate of different nozzle combinations

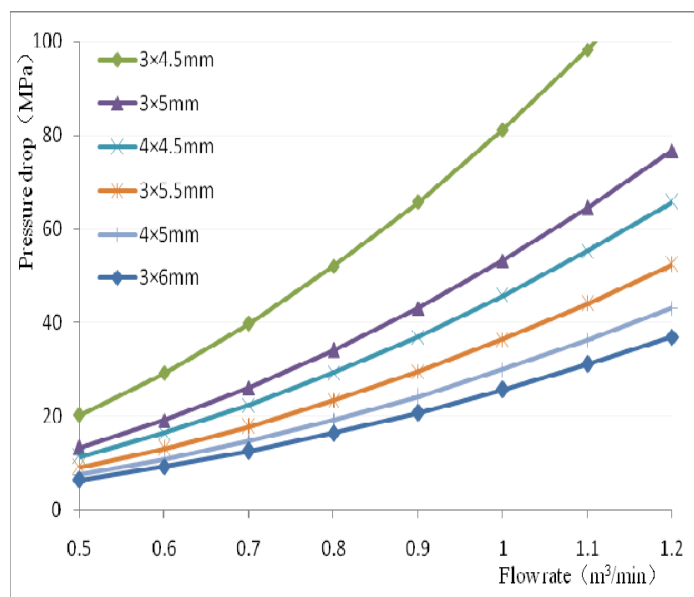

Figure.7 Diagram of relationship between pressure drop and flow rate of different nozzle combinations

The simulation results show that the pressure drop of the nozzle increases with the increase of nozzle displacement with the same nozzle diameter. The more nozzles there are, the smaller the pressure drop will be. When the number of nozzles is constant, the larger the diameter of the nozzles, the smaller the pressure drop of the nozzles.

The construction displacement and ground pressure of different nozzle combinations are determined by combining numerical simulation and hydraulic acid spraying experiment results. 


\section{Conclusion and cognition}

(1) The reservoir is highly heterogeneous and the damage zone is not evenly distributed. In combination with the damage form of horizontal Wells, the spindle-type acid distribution method can be adopted to enhance the effectiveness of measures.

(2) The deep penetration ability of the acid system is the primary condition to solve the acid plugging of long horizontal Wells in the upper reservoir of Oil field A. The amino carboxylic acid system synthesized in the laboratory has strong chelating ability to metal ions in carbonate reservoirs and excellent corrosion inhibition effect, which is conducive to the deep penetration of the acid system.

(3) Combined with the characteristics of the target reservoir and the completion method, the acidizing process suitable for horizontal Wells in the upper layer of Oil field A was proposed: amino carboxylic acid system + coiled tubing hydraulic jet acidizing process. It is suggested that the coiled tubing nozzle combination above 2 in should be $3 \times 6 \mathrm{~mm}$. Combined with the depth of the well section, the coiled tubing spiral section length should be reduced as far as possible, so as to effectively reduce the construction pressure on the ground and increase the construction discharge to achieve the purpose of deep penetration.

\section{Acknowledgments}

This work is funded by external cooperation project of Huabei oilfield, entitled "Research and application of foam polyhydroacidizing technology in low pressure carbonate reservoir" (No:2019-HB-F14)

\section{References}

1. Wang Xugang, Zhang Wenhua, Li Yingguang, et al. Rapid Drilling Technology in Ahdeb Oilfield[J]. Petroleum Drilling Techniques, 2013, 41(1): 35 39.

2. Wang Xing. Additives for acidification of reservoirs used abroad[J]. Drilling Fluid \& Completion Fluid, 2010(1): 75-78.

3. Buijse $\mathrm{M}$ A. Understanding wormholing mechanisms can improve acid treatments in carbonate formations [J]. SPE 38166, 1998.

4. MENG Lianxiang, LIU Hongxing, JIANG Yong, et al. Optimization of Temporary Plugging Diversion Technology during Horizontal Well Acidization[J]. Drilling \& Production Technology, 2013, 3 (65): 100-102.

5. Liao Hualin, Li Gensheng, Niu Jilei Influential Factors and Mechanism Analysis of Rock Breakage by Ultra-high Pressure Water Jet under Submerged Condition[J]. Chinese Journal of Rock Mechanics and Engineering, 2008, 06: 1243-1250. 